\title{
SELF-ESTEEM IN ADOLESCENTS
}

\author{
M. Minev*, B. Petrova, K. Mineva, M. Petkova, R. Strebkova \\ Department of Medical Psychology and Foreign Languages, Medical Faculty, Trakia University, \\ Stara Zagora, Bulgaria
}

\begin{abstract}
PURPOSE. Self-esteem is an overall evaluation of the person's value, expressed in a positive or negative orientation towards himself. Its development starts from birth and is constantly changing under the influence of experience (1). Especially important is the role of self-esteem in the process of adolescence. During this period, it correlates with both academic achievement and mental health. The aim of this study is to analyze the correlation between academic achievement and self-esteem among teenagers. Forty 14year-old students (20 boys and 20 girls) with excellent, very good and good results in school were examined. Methods: Self-Esteem Scale (RSE) (2). The study results show that girls have significantly more negative attitudes towards themselves $(\mathrm{x}=32.25)$ comparing with boys $(\mathrm{x}=25.14)$. These results support the need for further research to explore how individual and contextual factors affect the development of self-esteem over the school years.
\end{abstract}

Key words: self-esteem, adolescence, academic achievement, self-perception

\section{INTRODUCTION}

Self-esteem is an overall assessment of the individual's worthiness, expressed in a positive or negative orientation towards them. It is a component of the Self-concept that Rosenberg (2) defines as a totality of individual thoughts and feelings, having reference to him as an object. Besides self-esteem, self-efficacy and self-identification are an important part of the Self-concept. Self-esteem as a whole is an unchanging feature of adults and it is difficult to be influenced by the experimental design of a study (3).

The synonyms of the term self-esteem are: 1) self-importance; 2) self-respect; 3) self-love (which may contain elements of pride); selfcompleteness. Self-esteem, however, differs from self-confidence and self-efficacy which include conviction in terms of personal qualities and future performance. In the mid1960s Maurice Rosenberg and the supporters of the social learning theory (2) define selfesteem as a stable sense of self-worth. This is the most commonly used definition, the main difficulty being in distinguishing it from

\footnotetext{
*Correspondence to: Milen Minev, Department of Medical Psychology and Foreign Languages, Medical Faculty, Trakia University, 11 Armejska Str., Stara Zagora, 6000 Bulgaria.Tel.: +359 886622101; E-mail: m_minev@abv.bg
}

narcissism and bragging. In 1969 Nataniel Brenden (4) defined self-esteem as the disposition to experience oneself as being competent to cope with basic challenges of life and as being worthy of happiness (5). This two-factor approach, as some call it, offers a definition limiting self-esteem within the limits of competence and worth alone. Branden's descriptions of self-esteem are as follows (4):

- $\quad$ Self-esteem is a fundamental human need; it is part of the process of life and is indispensable to normal and healthy selfdevelopment and is vital for survival.

- Self-esteem is an automatic and inevitable consequence of the individual's choices.

- Self-esteem is a part of, or a background to individual's thoughts, feelings and actions.

Self-esteem is a part of our personality and in order or raise it we need to have a sense of personal worth coming from those life challenges that demonstrate our success (6).

Self-esteem has two elements - selfknowledge and self-awareness. It included the individual's perceptions about their own strengths and weaknesses, abilities, attitudes and values. Its development starts at birth and is constantly developing under the influence of experience (1). During different periods of human age the child realizes one or other side of their own self. The child becomes aware of 
MINEV M., et al.

their skills and practical abilities first - motor skills, artistic abilities, performing skills. Children start becoming aware of their personal traits at a significantly later stage in life. The process starts when all moral and social benchmarks for assessment have been acquired. That can be explained with the complexity and ambiguity of results from the manifestation of personal qualities. Children become aware of their personal peculiarities and traits in the communication process with adults and peers. This process of selfawareness is the most active in adolescence (7).

Adolescence is a crucial, critical period in individual's development, a transition period between childhood and adulthood in a particular cultural environment. Self-esteem plays a very important role for development during this period.

High self-esteem has no positive effect on school performance (8). A study (9) even showed that artificially inflated self-esteem leads to poorer school performance.

Self-esteem is a fundamental component of self-awareness. It occupies a key place in the structure of adolescent individual because it is related to mental health and definition of life goals (10). Processes related to the formation and development of self-esteem determine the perimeters of the relationship between the adolescent and the surrounding world, contribute to the development of their competence and the quality of the activities performed. These processes should not be random; they should be smooth so that the adolescent can build and adequate self-esteem. The more realistic is it, the more adaptable the adolescent will be (11).

Self-esteem is the subject of M. Rosenberg's research. Studying high school students with the help of a 10-item assessment scale (Rosenberg Self- Esteem Scale) Rosenberg found that higher self-esteem is largely determined by parents' interest in their own children (2). The self-assessment study model based on the discrepancy between the real and ideal self, considers the lack of correspondence between them as a result of having unrealistically high ideal standards in a given field or as a result of the individual's perception of insufficiently good performance in a certain area (12). When the individual thinks that their real and ideal selves are incompatible they try to reduce the discrepancy between them as "the search for self-worth is one of the strongest motivation forces in the adolescent and adult human behavior", the realization of which is connected with significant individual differences (13). Chronic perception of discrepancy between the ideal and real self is associated with frustration, inferiority and depression.

The social situation on which the adolescent's mental development depends is largely determined by the family. Parents and older family members need to know the specifics of adolescence and seek to help the child overcome their difficulties, treating the future full citizen with love, respect and trust (14). Parents should help their children while overcoming learning and communication difficulties; they should give honest and sincere answers to multiple questions, related to intimate, social and moral issues. Love and trust, competent answers and advice are the parents' fundamental "tool" helping their children become an adult and equal to them individual. The ability to understand contradictory facts and situations affects the relationships between adolescents and their parents. The adolescents compare images of ideal parents with the real parents they watch every day. They are often critical of social institutions, including family and parents. A number of facts have been identified:

- Overly strict parenting and satisfaction of all needs are associated with earlier onset of sexual activity of adolescents. Moderate parental strictness leads to the best results (15). Sexually active adolescents often report bad relationships with their parents.

- The number of family disputes increases. Battles fought over everyday activities (household chores, dressing, learning, family meals) allow the adolescents, through relatively minor problems, to check the degree of their independence in a safe family environment. The word "negotiation" is one of the most important words at this age. Most psychologists, instead of talking about rebellion and painful separation from the family, prefer to describe the period as one during which parents and kids negotiate new relationships between them (15). Adolescents, feeling strongly about their individuality are brought up in families where parents not only offer guidance and success, but let their children express their own views.

- One aspect of thinking on the level of formal operations is the ability to analyze one's own thought processes. A particular type of egocentrism is being expressed. 
Adolescents tend to believe that their behavior is as interesting to others as to themselves. They are not good at putting boundaries between their own interested and those of other people. Adolescents are extremely worried about what other people will learn about their shortcomings. The idea that other people are constantly observing and evaluating their behavior has been called imaginary audience. It is a common cause of shyness and painful response to the opinions of other people (15).

To conclude we may say that self-esteem is central to what we do with our lives - the loyalty we have to developing ourselves and caring for others - and is at the heart of everything that an adolescent will achieve in their life. Self-esteem is formed in the family by the parents and parental attitude is of paramount importance. Self-esteem will influence the adolescent's performance at school; it will determine how competent the child will be, to what extent that child will be accepted by others and what acceptance they will demonstrate in turn.

The aim of this study is to analyze the correlation between successful academic achievement and self-esteem in adolescent students.

\section{METHODOLOGY}

\section{People included in the study}

40 eight-grade students from the Ivan P. Pavlov Professional High School of Veterinary Medicine - Stara Zagora were included in the study. The participants in the study were 14 years old and the sex distribution was as follows: boys- 20, girls -20 . The participants were distributed on the basis of their school performance as follows: 15 students with excellent grades, 15 students with very good grades and 10 students with good grades.

\section{Methods}

I. Psychology research tools:

1. Rosenberg Self-esteem Scale. (RSE) (2). Adapted and standardized for Bulgarian conditions by Professor H. Silgidzhiyan. The
MINEV M., et al. questionnaire has proven reliability and validity (Cronbach's coefficient $-\alpha=0,690$ ), indicating high internal consistency of the scale. It is designed to measure the level of self-esteem (16).

The questionnaire includes 10 items which are ranked on a scale of 4 self-esteem points at the time of the study. Scores are calculated as follows: 4 - strongly agree; 3 - agree; 2 disagree; 1 - strongly disagree. Higher scores are indicative of high self-esteem level, while lower ones indicate lower self-esteem.

\section{Statistical analysis}

Empirical data were processed with the SPSS statistical program. Descriptive statistics and correlation analysis were used.

\section{RESULTS AND DISCUSSION}

Scientific literature on studies conducted with respect to self-esteem of Bulgarian adolescents is scarce. Therefore, the interest in this area is not exhausted and the problem is yet to be studied. The gender differences found by Silgidzhiyan are being confirmed in a more recent study conducted by Zhorzh Balev with 292 Bulgarian adolescents aged between 13 and 19, using Rosenberg Self-esteem Scale (17). Results show that girls demonstrate a comparatively lower self-esteem level $(\mathrm{x}=32,76)$ as compared to boys $(\mathrm{x}=33,74)$.

Gender has its impact on adolescents' selfesteem as well. When compared to boys, girls seem especially vulnerable regarding the level of their overall self-esteem. Girls tend to have significantly more negative attitude to themselves as compared to boys. Results show that girls regard themselves more negatively $(\mathrm{x}=32,25)$ than boys $(\mathrm{x}=25,14)(18)$.

Achieving and maintaining a high and stable self-esteem is a special type of challenge for adolescents at that age.

The results of the present study show gender differences in the self-esteem scores of the students included in the study. It confirmed the fact that boys have higher level of self-esteem than girls (Table 1).

Table 1. Comparison of gender-based self-esteem scores

\begin{tabular}{|c|c|c|c|c|c|}
\hline \multirow{3}{*}{ Self-esteem } & Gender & $\begin{array}{c}\text { Average } \\
\text { score }\end{array}$ & $\begin{array}{c}\text { Standard } \\
\text { deviation }\end{array}$ & $\begin{array}{c}\text { Student's } \\
\text { coefficient t-test }\end{array}$ & $\begin{array}{c}\text { Level of } \\
\text { significance }\end{array}$ \\
\cline { 2 - 6 } & girls & 32,72 & 0,53 & 2,49 & p $<0,01$ \\
& boys & 25,72 & 0,53 & \\
\hline
\end{tabular}


Boys regard themselves as more independent and worthy than girls; they look more selfassured and for that reason they seem to have fewer problems. That does not mean, however, that boys have no feelings, concerns or doubts. It is simply indicative of the fact that boys cope better in the emotional sphere than girls. This is consistent with results from previous studies, revealing statistically significant differences between the two groups (19).
MINEV M., et al.

Researchers explain lower self-esteem in adolescent girls with the fact that boys tend to be more independent from the opinion of others, while girls are more prone to conformism $(x=31,44)$ as compared to boys $(\mathrm{x}=26,41)(19)$.

No difference in self-esteem scores in both genders was found regarding the average school performance $(\mathrm{t}=0,44 ; \mathrm{x}=34,56 ; \quad \mathrm{p}$ $<0.01$ ). The difference found is small and statistically insignificant (Figure 1).

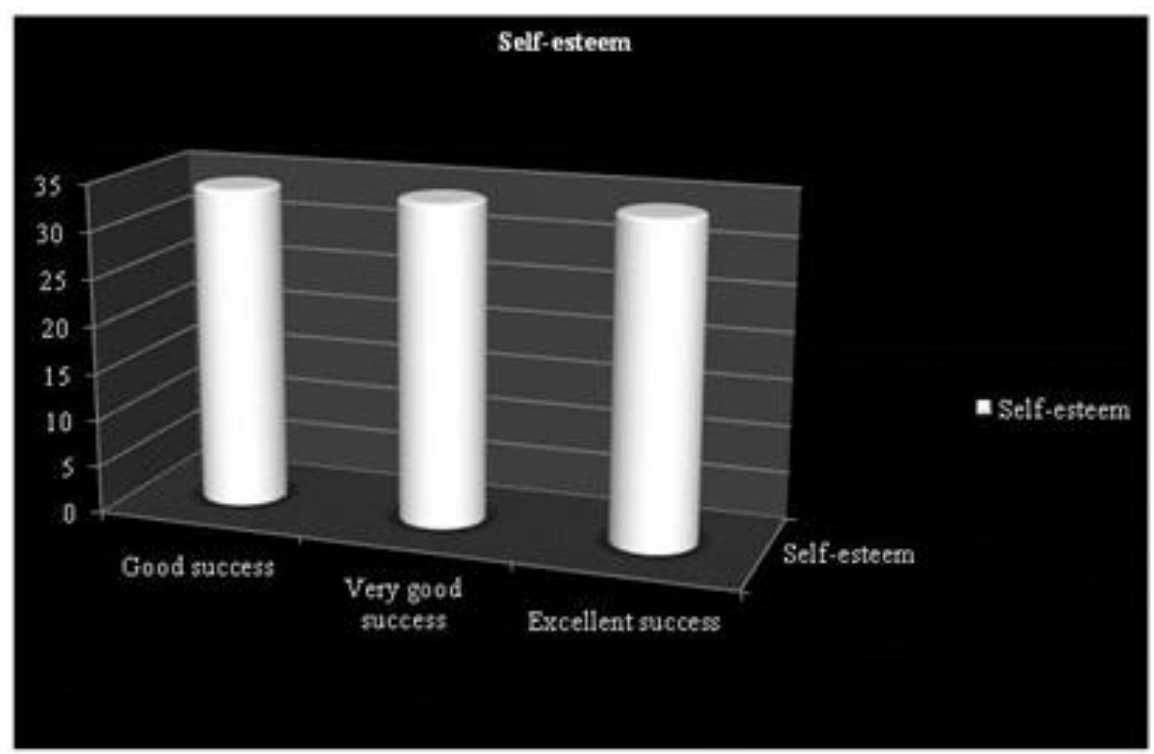

Figure 1. Students' self-esteem scores based on school performance

Studies investigating differences in self-esteem and self-concept in adolescents that have been cited above show that positive self-esteem at that age can be associated with personal qualities helping the individual in their selfexpression, self- realization and selfaffirmation (20), the gender influencing the level of self-esteem (16). Our results also show that gender affects the levels of self-esteem.

\section{CONCLUSIONS}

1. The level of self-esteem differs according to gender. Boys have a higher self-esteem than girls.

2. School performance has no impact of selfesteem levels of the students included in the study.

\section{REFERENCES}

1. Leavitt, P. A., Covarrubias, R., Perez, Y. A., \& Fryberg, S. A. (2015). "Frozen in time": The impact of Native American media representations on identity and selfunderstanding. Journal of Social Issues, 71, 39-53.

2. Rosenberg, M. (1965). Society and the adolescent self-image. Princeton. NJ: Princeton University Press, 2-34.
3. Coopersmith, S. (1967). The Antecedents of Self-Esteem. San Francisco, CA: WH Freeman.

4. Branden, N. (1969). The Psychology of Self-Esteem. San Francisco, CA: WH Freeman.

5. Keith, L.K., Bracken, B.A. (1996). Selfconcept instrumentation: a historical and evaluative review. In: Bracken BA, ed. Handbook of Self-Concept. New York, NY: John Wiley \& Sons, Inc, 91-171.

6. Emler, N. (2001). Self-Esteem: The Costs and Consequences of Low Self-Worth. York, United Kingdom: York Publishing Services.

7. Covarrubias, R., \& Fryberg, S. A. (2015). The impact of self-relevant representations on school belonging for Native American students. Cultural Diversity and Ethnic Minority Psychology, 21, 10-18.

8. Cvencek, D., Greenwald, A. G., \& Meltzoff, A. N. (2016). Implicit measures for preschool children confirm selfesteem's role in maintaining a balanced identity. Journal of Experimental Social Psychology, $62,50-57$.

9. Kinderman, P. R., Bentall, P. (2000). Selfdiscrepancies and causal attributions: 
Studies of hypothesized relationships. The British Journal of Clinical Psychology, (39), (3), 255-274.

10.Dunham, Y., Baron, A. S., \& Banaji, M. R. (2007). Children and social groups: A developmental analysis of implicit consistency in Hispanic Americans. Self and Identity, 6, 238-255.

11.Heatherton, T. F. (2001). Body image and gender. International Encyclopedia of the Social and Behavioral Sciences. Oxford, UK: Elsevier, (2), 1282-1285.

12.Moretti, M. M., Higgins, E. T. (1990). Relating self-discrepancy to self-esteem: The contribution of discrepancy beyond actual-self ratings. Journal of Experimental and Social Psychology, (26), 108-123.

13.Marsh, H. W. (1993). Relations between global and specific domains of self: The importance of individual importance, certainty and ideals. Journal of Personality and Social Psychology, (65), (5), 975-992.

14.Adler, A. (1996). Individual psychology, Part I. Sofia: Eurasia.
MINEV M., et al.

15.Craig, M. (2000). Psychology developments. Moscow: Pieter.

16. Silgidzhiyan, H. (1998). I-concept and psychosocial identity. The Life Transition to Maturity. S., IM "St. Kliment Ohridski ".

17.Balev, G. (1996). Prerequisites and incentives for a democratic pedagogical climate in labor-educative schools and homes for children and adolescents. Research report. Unpublished material.

18.Quatman, T. \& C.Watson (2001). Gender differences in adolescent self-esteem: an exploration of domains. Journal of Genetic Psychology, 162, Issue 1, 93-118.

19.Nasir, N. S., \& Bang, M. (2012). Conceptualizing cultural and racialized process in learning. Human Development, 55, 247-249.

20.Stoycheva, K., Zhelyazkova-Koinova, G. (1992). I-image and need for achievement in students with creative achievements. Bulgarian Journal of Psychology, №2, 3-9. 